TAJ June-December 2012; Volume 25

Published on 2016

ISSN 1019-8555

The Journal of

Teachers Association

RMC, Rajshahi

\title{
Editorial
}

\section{Quality Assurance in Medical Education}

\section{Zahirul Haque ${ }^{1}$}

'Physicians of tomorrow are taught by teachers of today using curricula of yesterday

\section{- K R Sethurman}

Quality of medical education, performance of medical students and graduates and provision of effective health care are interrelated. We always concerned about physicians performance and the care they render to the people and frequently we talk about the quality of medical care but rarely about the quality of education in the country.

Quality assurance in Medical Education is one means of maintaining or improving standards of health care deliver. Principles of QA Scheme include accountability, external review and self -evaluation.

Currently MBBS Course is monitored and evaluated at national level by DGHS, MOHFW, BMDC and Medical Faculty of Dhaka, Chittagong, Rajshahi, \& Shahjalal Universities. Local QA framework includes Academic Council, Course Committee, Phase Co- ordination Groups -Phase I, II \& III and External Examiners.

Recently there is a boom of medical education in both public and private sector despite the lack of necessary resources to run them. It may compromise the quality of the medical graduate which should be avoided by any means. One solution may be the formation of dedicated National Quality Assurance Body which will oversee QA in Medical Education and ensure that standards are maintained in all Medical Colleges through frequent visits to each Medical College.

Challenges faced by medical education in Bangladesh are pedagogical, structural, socio-economic and policy related. To maintain the quality of medical education in Bangladesh lots of issues are to be taken into consideration. For smooth functioning of quality assurance scheme in medical institutes strong commitment from policy level is very essential. Dedication to the profession as well as high moral on the part of the teachers is of utmost importance for better practices of quality assurance in different govt. \& non govt. Medical \& Dental Colleges in Bangladesh.

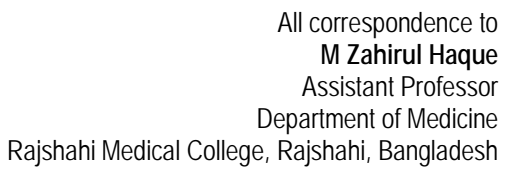

${ }^{1}$ Assistant Professor, Department of Medicine, Rajshahi Medical College, Rajshahi. 